\title{
SELETIVIDADE ESPACIAL DAS POLÍTICAS PÚBLICAS E O TERRITÓRIO URBANO - ALGUMAS REFLEXÕES.
}

\author{
SPATIAL SELECTIVITY OF PUBLIC POLICIES AND THE \\ URBAN TERRITORY - SOME THOUGHTS
}

\author{
André Santos da Rocha* \\ UFRRJ \\ asrgeo@ufrrj.br
}

\begin{abstract}
Resumo
O presente artigo tem o objetivo de traçar algumas reflexões sobre a espacialidade das políticas públicas pensando o território urbano como categoria operativa. Pensar o território urbano remete-se ao exercício dos direitos e da soberania dos sujeitos no urbano de forma territorializada. Essa categoria operativa nos permite: a) entender como os diferentes interesses na aplicabilidade das políticas públicas se revela em uma distribuição desigual e seletiva no espaço; e b) analisar a validade das políticas públicas seja na garantias dos direitos civis seja na desconstrução das formas de manutenção de interesses particulares. Para pensar tais questões, além de uma breve reflexão teórica sobre políticas públicas, direitos humanos e o urbano, exemplificaremos algumas práticas das políticas públicas na Baixada Fluminense, área que é parte integrante da região metropolitana do Rio de Janeiro.

Palavras-Chaves: Políticas Públicas, Direitos Humanos, Território Urbano, Seletividade Espacial, Baixada Fluminense.
\end{abstract}

\footnotetext{
Abstract

The present article aims to present some thoughts about the spatiality of public policies refers to the exercise to the rights and sovereignty of subjects in urban territoriality form. This operational category allows us to: a) understand how different interest in the applicability of public policies in space reveals itself in an unequal distribution and selective; and b) analyze the validity of public policies is in civil rights guarantees, is in the deconstruction of forms of special interests. To think such issues besides a brief theoretical reflection about public policies, human rights and urban, shall illustrate some region of Rio de Janeiro. Baixada Fluminense

Geo UERJ - Ano 14, nº 23 , v. 1, $1^{\text {o }}$ semestre de 2012 p. 99-113

ISSN: 1415-7543 E-ISSN: 1981-9021

http://www.e-publicacoes.uerj.br/index.php/geouerj
} thinking the urban territory as an operational category. Think of the urban territory practices of public policy in Baixada Fluminense, an area that belongs a metropolitan

Key words: Public Policies, Human Rights, Urban Territory, spatial selectivity, 


\section{Considerações iniciais - Políticas Públicas na Produção do Espaço Urbano.}

A reflexão a respeito da produção do espaço urbano associada a ação dos agentes produtores do urbano não é nova. Os trabalhos de Corrêa (1993; 2001), Castells (1980) e Carlos (2002) são alguns exemplos de apontamento teóricos sobre tal relação e, em síntese, indicam alguns grupos e instituições que se revelam como importantes agentes na/da produção e reprodução do urbano. A saber: o Estado, dos agentes imobiliários, dos agentes fundiários, instituições fabris e até mesmo os grupos segregados.

Neste direcionamento, muito se tem discutido sobre o papel geoeconômico destes agentes na (re)estruturação do espaço urbano. Destacam-se os trabalhos de Soja (2000), Massey (1984), Silva (2006), Oliveira et. all. (2006) onde os papeis dos grupos empresariais e dos agentes imobiliários ganham notoriedade. Em outros trabalhos como Davis (2006) e Castells (1980) são destacados a oportuna ação do Estado e de grupos segregados nessa reprodução do urbano. Porém, tais ações salientadas são arraigadas ora a produção sistemática da lógica capitalista de produção, em especial na ação do Estado como concordante com o pilar da estrutura geoeconômica, ora como reflexo desta (re)produção desigual que atribui-se a uma lógica de uso do espaço em condições marginais pelo grupos segregados.

Neste sentido, observa-se que faltam reflexões sobre a estrutura dialógica da ação destes agentes no espaço urbano, que não se reverberam apenas na lógica de consumo e produção econômica. Existe no urbano a dimensão geográfica da vida política e pouco se reflete sobre a acessibilidade, integralidade, efetividade dos direitos sociais e humanos que de alguma forma não efetivam a construção plena da cidadania pela forma seletiva em que as políticas públicas se espacializam no urbano.

Esta seletividade é diretamente imbricada com interesses ora convergente ora divergentes entre diferentes grupos sociais. Que acabam, também, por produzir e reproduzir o urbano, seja na materialidade de suas práticas seja na representação de sua obra (LEFEBVRE, 1972). Desse modo, lançamos pelo menos dois questionamentos

\footnotetext{
Geo UERJ - Ano 14, no. 23, v. 1, $1^{\text {o }}$ semestre de 2012 p. $99-113$ ISSN: 1415-7543 E-ISSN: 1981-9021 http://www.e-publicacoes.uerj.br/index.php/geouerj
} 
centrais para encaminhar este trabalho: a) como podemos pensar as políticas públicas a partir de uma reflexão geográfica no urbano?; e b) de que forma essas políticas públicas se apresentam no urbano e que exemplos podem ser evidenciados?

Para pensarmos as políticas públicas na produção do urbano, necessitamos pensar como de fato se revela o urbano.

Ao refletir sobre o urbano como uma combinação contraditória de desconstrução e reconstrução onde formas e processos espaciais se articulam com as ações de múltiplos agentes produtores do espaço urbano (SOJA, 1993). E que este é composto por práticas e representações (LEFEBVRE, 1972) podemos encaminhar um direcionamento: se entendemos as políticas públicas como práticas dos grupos sociais, perceberemos que a efetividade de tais políticas públicas carregam em produzem além de formas, também, conteúdos.

Ainda, se pensarmos numa concepção alargada de políticas públicas (BARBOSA, 2008) onde além do Estado outros agentes podem também ser promotores delas. E que estas se processam em convergência e divergência de interesses. Podemos, também, entender que estas podem se revelar de forma desigual do espaço urbano.

Desse modo, se buscarmos entender que as políticas públicas são práticas espaciais, podemos pensar a relação das políticas públicas na produção do espaço urbano, uma vez que este é também o produto das práticas de diferentes grupos sociais (CARLOS, 2002, LEFEBVRE, 2001). Ou seja, entender as políticas públicas como práticas espaciais, pode nos servir como importante recurso metodológico para pensar suas aplicabilidades e integralidades nas resoluções dos problemas relativo à afirmação dos direitos na cidade.

A associação entre práticas espaciais e as políticas públicas expõem o projeto intrinsecamente político que possui o espaço. Até mesmo porque não podemos pensar o espaço sem pensar as relações de poder (RAFFESTIN, 1993; FOULCAULT, 2009 ; 1985).

Segundo o próprio Foucault (2009) o poder só pode ser entendido em seu exercício, ou seja, em sua prática. Assim, as práticas espaciais não são ingênuas, não envolvidas em teias de relações de poder. Segundo Corrêa (1993) as práticas espaciais podem diferenciar segundo o propósito, mas não são em si excludentes. Neste mesmo 
sentido, Moreira (2007) aponta diferentes práticas espaciais, afirmando que estas têm por base o binômio localização-distribuição. Entre elas estão: a seletividade espacial; fragmentação - remembramento espacial; antecipação espacial; marginalização social.

Para fins metodológicos, tendo em vista, a brevidade desta exposição, selecionaremos apenas a seletividade espacial como prática para pensar as políticas públicas e o urbano. Que em síntese se revela como "o processo de eleição do lugar e do(s) respectivos recursos que iniciam a montagem da estrutura espacial das sociedades" (MOREIRA, 2001 p.2).

Assim, se pensarmos que as políticas públicas são práticas espaciais, podemos apontar que a afetividade delas contribuem com a produção do urbano. Além disso, nos indica que como prática espacial esta pode produzir diferenciações uma vez que sua aplicabilidade está diretamente associada a jogos de interesses entre diferentes grupos que imprimem uma seletividade espacial na distribuição de serviços básicos, e muitas vezes, a sua não efetividade, se revela como uma estratégia política no urbano onde a ausência da política pública é o algoz da marginalização espacial e da não integralidade dos direitos.

Contudo para refletirmos melhor sobre políticas públicas, é necessário pensarmos na perspectiva dos direitos e ainda o urbano não apenas como um "tecido urbano", mas como espaço que é permeado por relações de poder.

\section{Políticas públicas, direitos humanos e território urbano}

Em primeiro lugar julgamos ser necessária uma delimitação acerca da idéia de políticas públicas. Acreditamos que a vaguidade sobre esse termo que muitos utilizam em discursos e práticas políticas não ganham maior precisão pelo simples fato de entendê-la com uma "ação para o povo" (ALAYON, 2000).

De um lado isso se expressa por uma via positiva, onde as políticas públicas aparecem em caráter emergencial, sobretudo na erradicação da miséria, de outro por uma via negativa por não consolidar as políticas públicas como intrínseca a manutenção e integralidades dos Direitos Humanos (SAULE JUNIOR, 2007). 
Neste sentido, entendemos as políticas públicas como o instrumento capaz de garantir a integralidade dos Direitos Humanos, que em suma são territorializados no espaço. Barbosa (2008, p.13) ainda complementa afirmando que "a política pública deve ter como referência fundamental a proteção, promoção e reparação de Direitos declarados e garantidos na forma da Lei, e ao mesmo tempo, deve ser uma resposta às demandas sociais por novos Direitos".

Em suma as políticas públicas servem para intervir na realidade sócio-espacial e efetivar Direitos. Tais políticas podem ser classificadas assim como "públicas", entre outras coisas, quando: as decisões são públicas, ajuda a garantir o interesse público, é construído num debate amplo, e servem como promoção a igualdade de Direitos Humanos.

Direitos esses que são necessários a prática da cidadania. Em excelência são parâmetros que orientam os arranjos sociais e as condições políticas para a realização da dignidade humana. Esses direitos são caracterizados por si por serem universais, indivisíveis, interdependentes, exigíveis e justificáveis (MNDH, 2004).

Entres os direitos humanos e sociais que se materializam no espaço urbano estão o direito a saúde, moradia, cultura, segurança, trabalho e renda e educação. Tais direitos configuram uma trilha de indissociabilidade, onde sem a garantia plena destes não se constitui a consagração da cidadania.

Milton Santos (2007) destaca em seu livro "O espaço do cidadão", que o respeito ao indivíduo é a consagração da cidadania não vem apenas no ato de nascer, mas de torna-se ser no mundo. Aponta-se então prerrogativas que compartilham o "direito ao teto, à comida, à educação, à saúde, à proteção contra o frio, a chuva, as intempéries, direito ao trabalho, à justiça, à liberdade e a uma existência digna" (SANTOS, 2007:19).

A questão problemática para o direcionamento das políticas públicas está contida justamente no modo como estas se espacializam e na forma com ela é conduzida.

O urbano no Brasil, assim como em toda América Latina é marcado por grandes contrastes sociais. Nele se reproduzem redes políticas capazes de capitanear a pobreza e a não afirmação de direitos como pilares políticos para a manutenção de certo "poder". 
As práticas espaciais como políticas públicas são utilizadas não para a afirmação de direitos, mas para a manutenção do status quo político e econômico. Entende-se ai que as políticas públicas acabam sendo direcionadas de forma fragmentada, privatizada, clientelista e individualizada.

O urbano ganha então uma dimensão de disputa e mesmo de controle. $\mathrm{O}$ território como um conceito chave na geografia (CORREA, 1995), nos serve como numa idéia operativa. Pensar em território urbano, nos possibilitar vislumbrar além de domínio e controle, pensar questões como soberania (SOUZA, 1995) e direitos. Assim como o poder é exercido, os direitos e a soberania também o são.

Lima (2008) ainda nos lembra que pelo fato das políticas públicas incidirem seletivamente no espaço geográfico, elas findam por reconfigurar os territórios. Isto se dá por que a aplicabilidade destas modelam feições no território em formas e conteúdos sociais redefinidos fixos e fluxos no espaço. As políticas públicas podem se configurar com recursos territoriais, capazes de delimitar um território (RAFFESTIN, 1993).

Em pensar essa perspectiva no urbano, a seletividade espacial das políticas públicas atribui a ele uma diferenciação, onde sua produção está imbricada com jogos de poder entre continuidade de interesses particulares e a afirmação plena de direitos no urbano.

Há uma contradição posta na forma como se conduz as políticas públicas, pois ela antagoniza o sentido de sua primeira palavra. Como uma política, por si só teria o sentido de Liberdade (ARENDT, 2009).

Como podemos pensar a liberdade dos sujeitos no urbano contemporâneo se as práticas "políticas" se revelam em aprisionamento ao não levar em consideração o caráter indivisível e interdependente dos Direitos? A concepção de um território urbano nos indica o ponto onde podemos pensar a soberania política dos sujeitos, não pela retomada do poder já entravado num pensamento colonial (SOUZA SANTOS, 2010), mas numa construção autocrítica das relações de coexistência (LIMA, 2009), pelo simples fato ser-no-mundo, que prescreve-se antes na exigibilidade integral dos direitos.

Ao discutir a noção de território urbano tendo como contexto as políticas públicas nos possibilita pensar em justiça territorial (LIMA, 2008) que se traduz na 
distribuição eficaz deste serviço sobre o território bem como na afirmação dos sujeitos que nele habitam em prol de uma emancipação social (HARVEY, 2006).

Assim, a idéia de território urbano pode servir como um importante recurso metodológico para analisar a relação de políticas públicas e o urbano, em especial para entender a relação plena do exercício dos Direitos. Assim, Para exemplificar essa perspectiva apresentaremos o caso da espacialidade das políticas públicas numa área inserida na região Metropolitana do Rio de janeiro, a Baixada Fluminense.

\section{Exemplificando a seletividade espacial das políticas públicas no urbano - o caso da Baixada Fluminense}

É sabido que a noção do que se conhece hoje como Baixada Fluminense foge do domínio que relaciona sua nomenclatura à definição de uma região natural (ROCHA, 2009). A idéia atual apresenta uma composição territorial que leva em consideração representações com parâmetros relacionados a dimensões políticas, sociais e econômicas, construídas no processo da expansão urbana do Rio de Janeiro. O que se associa, comumente, à Baixada Fluminense é a representação de alguns municípios que fazem parte da Região Metropolitana do Rio de Janeiro e que estão localizados na porção oeste da Baia da Guanabara. Hodiernamente, está área tem sua representação hegemônica vinculada a temas como morte, violência, medo, miséria etc. (ALVEZ, 1998).

Segundo Maria Therezinha de Segada Soares (1962), foi esta a porção territorial absorvida pela "célula urbana do Rio de Janeiro", intensificada pelas constantes ondas loteadoras, já apontada por Geiger e Mesquita (1956).

Atualmente percebe-se uma articulação regional para reivindicar uma série de benefícios aos municípios que "supostamente" fazem parte desta "Baixada". Vislumbrase uma constituição de uma geopolítica da inclusão - exclusão (LIMA \& ROCHA, 2010), onde a idéia de estar ou não estar na Baixada Fluminense se condiciona aos benefícios que esta composição pode oferecer. Ou seja, fazer parte da Baixada pode ser o critério de ter parte do seu município contemplado com alguma política pública. 
Entre os benefícios, que podem ser exemplificados e materializados, para pensar essa questão estão às políticas públicas na área de infra-estrutura urbana e saúde. Percebe-se que a territorialização dessas políticas, constitui uma manifestação espacial, onde o que é "baixada" está condicionado aonde essas políticas se espacializam.

No que tange as políticas públicas na área da infra-estrutura urbana, podemos pensar anos de 1990 que a Baixada Fluminense quando ganha maior notoriedade nas políticas de governo que se sucederam. Nesse período emergem políticas territoriais que criam uma Baixada Fluminense em seus recortes de intervenção, como são os exemplos dos programas Nova Baixada e Baixada Viva, e a criação de uma secretaria de governo da Baixada Fluminense que fosse capaz de criar um diálogo com o poder político local e o governo estadual.

A iniciativa de tentar promover essas políticas públicas para a "Baixada Fluminense" é na realidade uma forma de tentar estabelecer uma "certa" democratização no acesso a alguns serviços básicos na área de infra-estrutura urbana. Contudo os critérios utilizados para a localização/posição das políticas públicas no urbano metropolitano do Rio de Janeiro é condicionado às filiações políticos partidárias entre governos municipais e estaduais, onde o que se quer é capitanear os recursos econômicos e políticos que marcam essa área.

De forma geral podemos mencionar o fato de alguns municípios da Baixada como Nova Iguaçu, Duque de Caxias e Belford Roxo fazem parte daqueles que mais arrecadam entre os municípios no País. Além de que esta área representa mais de $36 \%$ do eleitorado do Estado do Rio de Janeiro. Ou seja, o controle político territorial desses recursos pode decidir uma campanha eleitoral para senador, deputados federais e estudais e até mesmo para Governador no estado do Rio de Janeiro.

As destinações das políticas públicas obedecem então como critério de seletividade algo que não condiz com política de exercício pleno dos direitos humanos. O programa Nova Baixada (ver figura 1) exemplifica a localização de provimento de saneamento básico para região metropolitana, porém não contemplou outros municípios da Baixada como Japeri e Queimados. Áreas que segundo o IBGE em 2002 tinha mais de $90 \%$ de sua população sem tratamento de Esgoto e água tratada. 


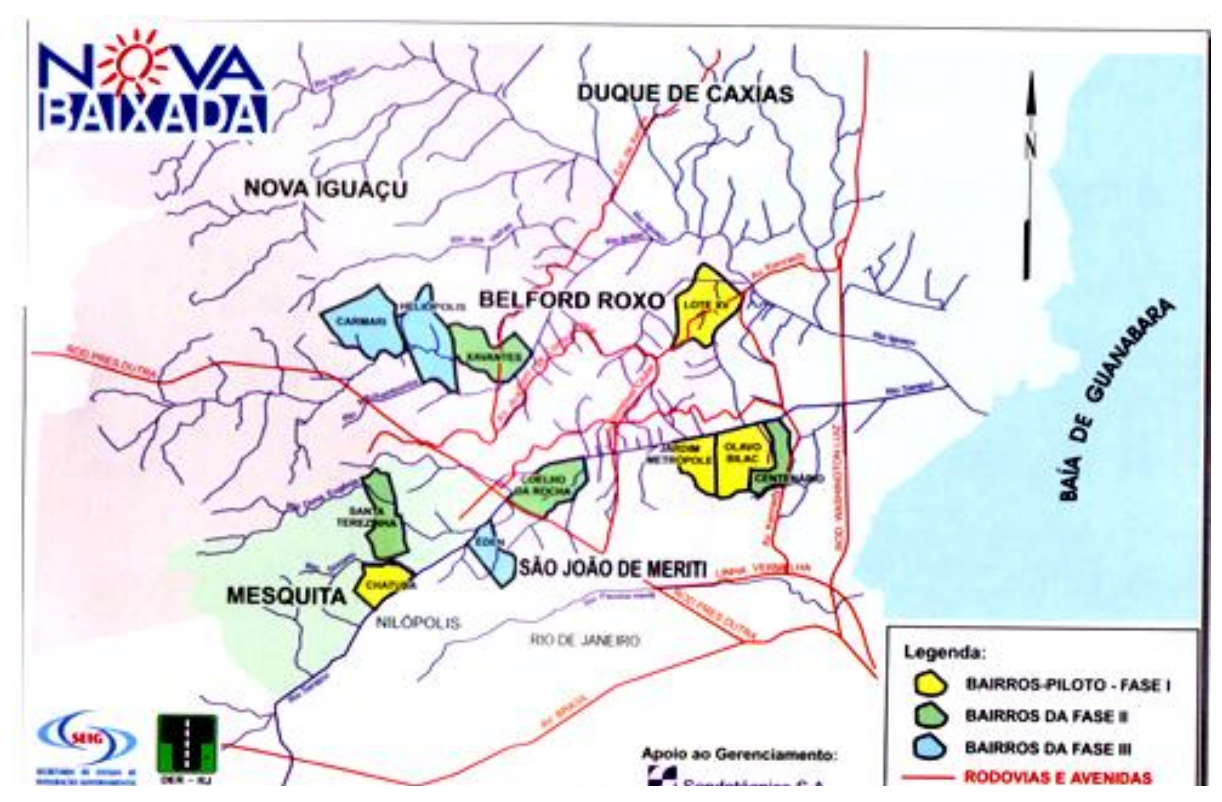

Figura 1 - Representação do plano de ação territorial do programa nova Baixada.

O programa em tela tinha como objetivo melhorar a qualidade de vida da população, particularmente suas condições de saúde e saneamento básico. Foram executados em alguns bairros dos municípios de Belford Roxo, Nova Iguaçu, Mesquita, Duque de Caxias e São João de Meriti. O programa ocorreu entre os anos de 1996 e 2005 (SEIG/DER-RJ)

Neste programa a escolha se deu entre outros fins na proximidade com a metrópole e nas relações políticas de afinidade entre o até então Governo Antony Garotinho e políticos locais. 
Uma questão levantada durante aplicação de entrevistas de campo com a população local junto ao Projeto Rio Democracia ${ }^{1}$ sobre o impacto dessas políticas públicas na área de Moradia nos locais onde o Baixada Viva teve sua localização, a maior parte da população identificou "melhoras" no que tange as noções de mobilidade acessibilidade de alguns bairros, e que também se repercutiu na área de Saúde diminuindo sensivelmente alguns índices de contaminação, índices elevados devido à falta de infra-estrutura no saneamento básico (água e esgoto tratado).

Esse dado revela a característica reparadora que contem a prática das políticas públicas solidificadas no exercício dos Direitos. Ação reparadora das políticas públicas mostra como a escassez destas se revela de um lado como um trunfo a ser usado por agentes políticos na constituição e delimitação de territórios particulares. De outro revela a dimensão-força que solidifica ação plena de que por mais que seja incipiente uma política pública ela é capaz de promover sensíveis mudanças no imaginário social e material de uma comunidade.

O exemplo de como uma política pública é utilizado como estratégias na delimitação de território particulares, pensando na idéia de territorialidade (SACK, 1986), podem ser exemplificadas nas estratégias utilizadas por deputados para conseguir ampliar sua rede de influência na Baixada. Segundo o Jornal Estado de Minas em 2003 e 2004 alguns deputados são levados a usar o Orçamento como Arma Eleitoral, ou seja, eram liberadas verbas de investimentos de diferentes políticas públicas para aqueles que pertenceriam a Baixada e ao grupo político que apoiaria² .

Monteiro (2002) já apontou a prática política de alguns agentes na Baixada. O referido autor traz a tona o debate que o fazer das políticas públicas acompanhavam a idéia da "rede de resolução de problemas práticos" onde a escassez das políticas públicas serviam como trunfo da afirmação do poder político institucionalizado. Dessa forma, o referido autor deixa claro como as políticas públicas ganham o processo inverso das perspectivas dos direitos (BARBOSA, 2008). Ou seja, ao invés de caminhar para a integralidade, exigibilidade e indissociabilidade dos direitos, as políticas públicas trilham sobre o paternalismo, o clientelismo, o assistencialismo que nutre a força políticas de algumas instituições e personagens políticos que fragmentam ainda mais a 
idéia de direito no urbano. Assim, o território urbano deixa de ser lugar da soberania cidadão para se delimitar em espaço de poder e controle de grupos políticos locais.

Pode-se ainda apresentar o caso das políticas públicas na área da Saúde que se desenrolam nessa área para exemplificar tais questões.

De um lado como tentativa de pensar políticas públicas descentralizadas na área da saúde como prevê o SUS (Sistema Único de Saúde), foi institucionalizado o consórcio CISBAF (Consórcio Intermunicipal da Saúde da Baixada Fluminense). Esse consórcio é formado por treze municípios (Belford Roxo, Mesquita, Nilópolis, São João de Meriti, Nova Iguaçu, Duque de Caxias, Japeri, Queimados, Paracambi, Magé, Paracambi, Seropédica e Itaguaí). O CISBAF possui um fórum contínuo de debates sobre a questão da saúde pública para a região. $\mathrm{Na}$ última pauta de discussão deste consorcio foi apresentada a criação de um "Hospital do Coração" que será localizado em Queimados, tendo em vista a eqüidistância entre os municípios participantes do consórcio ${ }^{3}$.

O exemplo das práticas do CISBAF coloca de alguma forma como podem ser articuladas ações de políticas públicas que vão incluir o poder público instituído, comunidade civil e instituições privadas, pensando uma articulação territorial em curso. Que toda via, pensa a questão das políticas públicas e sua seletividade espacial condicionada aos interesses do público na integralidade no acesso ao serviço de saúde.

Em contraposição, a prática de escassez das políticas públicas na mesma área coloca-se como um trunfo a ser capitaneado. O jornal O Extra de 24 de agosto de 2011 denunciou a situação da política pública na área de Saúde em Belford Roxo. Onde o Hospital Municipal não funciona e não têm médicos especializados, porém os centros assistenciais de vereadores do município funcionam plenamente, até com especialidades não encontradas no serviço público no município como cardiologistas e odontologistas. Como ponto agravante se coloca o fato de que o atendimento nesses centros comunitários está condicionado ao domicílio eleitoral contido em Belford Roxo. Assim, fazendo do acesso ao direito a saúde um trunfo delimitador de um território no urbano.

O caráter assistencialista nas políticas de saúde em Belford Roxo em contraste com a tentativa de democratização/descentralização proposta pelo CISBAF revela como são díspares as práticas e a espacialidade das políticas públicas. Onde de um lado 
prescreve-se a perspectivas assistencialistas e paternalistas e de outros a tentativa da integralidade dos direitos da saúde nessa parcela do urbano na região metropolitana do Rio de Janeiro.

\section{Para não concluir}

A seletividade espacial das políticas públicas e o debate a cerca da garantia dos direitos no urbano devem constar na agenda pesquisa daqueles que se debruçam sobre o urbano. Pensar o território urbano como categoria operativa nos permite pensar a validade das políticas públicas seja na garantias dos direitos civis seja na desconstrução das formas de manutenção de interesses particulares.

Os exemplos apresentados sobre as políticas públicas de infra-estrutura de urbana e saúde para a Baixada bem como na prática pela qual o poder local faz uso desta na manutenção de seus interesses particulares, nos indica que as políticas públicas são, ao mesmo tempo, parte produtora da materialidade e imaterialidade no urbano. Ou seja, produz o espaço urbano no provimento de equipamentos básicos, dimensionando fixos e fluxos pela seletividade espacial dos serviços, e, também, reproduz uma política no urbano contido no recurso simbólico de delimitação dos recursos eleitorais e políticos do espaço urbano.

Contudo, não queremos nesse breve artigo finalizar uma discussão sobre a relação entre políticas públicas e o urbano, mas se de alguma forma o esforço teórico apresentado juntamente com os exemplos foram capazes de encaminhar um debate, já nos damos por satisfeitos.

\footnotetext{
* Professor Assistente I do Departamento de Geociências da Universidade Federal Rural do Rio de janeiro. Lider do LAGEPPE - Laboratório de Geografia Política e Práticas Educativas. Doutorando em Geografia pela UFRJ, Mestre em geografia pela UFF, Especialista em políticas territoriais pela UERJ. Atua no campo da Geografia Política e Regional e Geografia Cultural, em especial no seguintes temas: território e representação, Baixada Fluminense, Políticas Públicas e Ensino de Geografia.
}

\section{Notas}

1 - Projeto Rio Democracia é um projeto de inventário das políticas sociais realizadas entre 1998 e 2008 região metropolitana do Rio de Janeiro que contou com apoio da Petrobrás e do Observatório de Favelas. (Ver mais em www.riodemocraria.org.br )

Geo UERJ - Ano 14, n⿳. 23, v. 1, $1^{\text {o }}$ semestre de 2012 p. 99-113

ISSN: 1415-7543 E-ISSN: 1981-9021

http://www.e-publicacoes.uerj.br/index.php/geouerj 
2 - Os campeões do clientelismo são do Rio de Janeiro [...] O petista Lindberg Farias, précandidato a prefeito de Nova Iguaçu, aprovou três emendas para o seu município. Serão R $\mathbf{7 5 0}$ mil para unidades especializadas em saúde, $\mathrm{R} \$ 950$ mil para a ampliação de oferta de cursos de graduação e R\$ 800 mil para a instalação de um espaço cultural. Sandro Matos (PTB), candidato em São João de Meriti, destinou R\$ 1,46 milhão ao Hospital de Caridade da cidade, R \$ 300 mil para a unidade de saúde do bairro Venda Velha, R\$ 740 mil para revitalização de áreas centrais. O suplente de deputado Fernando Gonçalves (PTB-RJ), outro candidato em Nova Iguaçu, cedeu a vaga na Câmara para o titular Miro Teixeira, mas deixou três emendas para o município. São R\$ 2,15 milhões dirigidos à Associação de Caridade Hospital Nova Iguaçu. (Jornal Estado de Minas de 11/04/2004)

3 - Informação prestada pelo próprio Prefeito de Queimados em Seminário organizado pela FIRJAN “O futura da Baixada em discussão” realizado em Nova Iguaçú no dia 15/08/2011.

\section{Referências}

ALAYON, N. Asistencia y asistencialismo. ¿ Pobres controlados o erradicación de

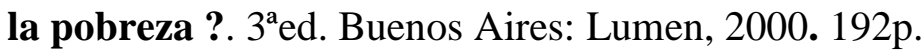

ALVES, J. C. S. Baixada Fluminense: a violência na construção do poder. $196 f$. Tese (Doutorado em Sociologia). Programa de Pós-Graduação em Sociologia/USP, 1998.

ARENDT, H. O que é Política. Rio de Janeiro: Bertrand Brasil, 2009. 240p.

BARBOSA, J. L. Cidadania, Território e Políticas Públicas. In: Segundo seminário do

Projeto Rio Democracia - caderno de textos. Observatório de Favelas: RJ, 2008. P. 12-14.

CARLOS, A. F. A. O consumo do Espaço. In: CARLOS, A.F.A (org.). Novos caminhos da Geografia. São Paulo: Contexto, 2002. p.173-186

CASTEllS, M. Cidade, democracia e socialismo. $2^{\circ}$ Ed. Rio de Janeiro: Paz e Terra, 1980. 193p.

CORREA, R. L. Espaço Urbano. São Paulo: Ática, 1993. 94p. 
- Espaço: um conceito chave da Geografia. In: Castro, Iná; CORRÊA, Roberto L.;GOMES, Paulo C. (Org's). Geografia: Conceitos e Temas. Rio de Janeiro: Bertrand Brasil, 1995. p.15-47

. Trajetórias Geográficas. Rio de Janeiro: Bertrand Brasil, 2001.

DAVIS. M. Planeta Favela. São Paulo: Boitempo, 2006.

FOUCAUlT, M. Microfísica do Poder. 26aed. Rio de janeiro: Graal, [1985] 2008. $295 \mathrm{p}$

Vigiar e punir. $37^{\mathrm{a}}$ ed. Petrópolis: Vozes, 2009. 291p.

GEIGER, Pedro P. \& MESQUITA, Myriam G.C. Estudos rurais da Baixada Fluminense. Rio de Janeiro: IBGE, 1956. 100p.

HARVEY, David. A produção Capitalista do Espaço. $2^{\mathrm{a}}$ Ed. Annablume: São Paulo, 2006. 251p.

LEFEBVRE, H. La production de l'espace. Paris: Maspero,[1972] 1974. 485p.

O direito à Cidade. $4^{\mathrm{a} e d . ~ S a ̃ o ~ P a u l o: ~ C e n t a u r o, ~ 2001 . ~ 145 p . ~}$

LIMA, I. G. Retorno crítico ao conceito de Território. In: $\mathbf{1 2}^{\mathbf{0}}$ Encuentro de Geógrafos de America Latina, 2009. Disponível em: <http://egal2009.easyplanners.info/programaExtendido.php?sala_=D\%20\%2038\&dia_=MART ES_AREA_1_2_3_4\#.> Data do acesso 23/02/2012.

LIMA, I. G. Território de Políticas Públicas. In: Segundo seminário do Projeto Rio Democracia - caderno de textos. Observatório de Favelas: RJ, 2008. P 9-11.

LIMA. I. G; ROCHA, A. S. Expressão Geopolítica da Baixada Fluminense : os trunfos de legitimidade territorial em jogo. In: Anais XVI encontro Nacional de Geógrafos. Crise, praxis e autonomia: espaços de resistência e de esperanças. AGB: Porto Alegre, 2010. p. $1-10$

MASSEY, D. Spatial division of labour. NewYork: Routledge, 1984. 393p.

MDNH - Cadernos de Estudos. Sistema Nacional de Direitos Humanos. Brasília, 2004.

MONTEIRO, L. A. Baixada Fluminense: identidades e transformações. Estudo de relações políticas na Baixada Fluminense. A criação do município de Belford Roxo e a mitificação política de seu primeiro prefeito. 254f. (Dissertação de Mestrado). Programa de Pósgraduação em História Social UFRJ/IFCS, 2002. 
MOREIRA, R. Para onde vai o pensamento geográfico. São Paulo: Contexto, 2007. p.192.

.As categorias espaciais da construção geográfica das sociedades. In:

GEOgraphia. Niterói, nº5, ano 3, p.1-18, 2001

OLIVEIRA, F. J. G. Mudanças no espaço metropolitano: novas centralidades e dinâmicas espaciais na metrópole. In: Oliveira, F.J.G.; SILVA, C.A;FREIRE, D.G(Org’s). Metrópole: governo, sociedade e território. Rio de Janeiro: DP\&A, 2006. P. 79-98.

RAFFESTIN, C. Por uma Geografia do Poder. São Paulo: Ática, 1993. 269p

ROCHA, A. S. Baixada Fluminense: representações espaciais e disputas de legitimidades na composição territorial municipal. 141f. (Dissertação de Mestrado Programa de Pós-Graduação em Geografia/UFF, 2009.

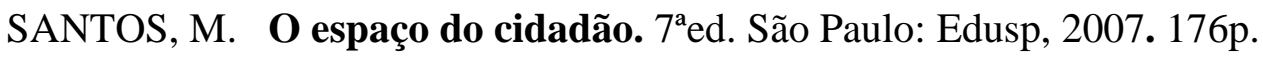

SAULE JUNIRO, N. Políticas públicas locais, municípios e direitos humanos. Disponível em http://www.dhnet.org.br/direitos/textos/politicapublica/nelsonsaoule.htm .Data do Acesso 17/06/2007.

\section{SECRETARIA DE ESTADO E INTEGRAÇÃO GOVERNAMENTAL DO RIO}

DE JANEIRO - SEIG. Programa Nova Baixada. Rio de Janeiro: SEIG/DER-RJ, 2005. SEGADA SOARES, M. T. Nova Iguaçu: absorção de uma célula urbana pelo Grande Rio de Janeiro. In: Revista Brasileira de Geografia. Rio de Janeiro: IBGE, vol2, n²4, p.155-256, 1962.

SILVA. W. R. Para além das cidades. Centralidade e Estruturação Urbana: Maringá e Londrina. 280f. (Tese de Doutorado). Programa de Pós graduação em Geografia/ UNESP, 2006.

SOUZA, M. L. O território sobre o espaço e poder,autonomia e desenvolvimento.In.: CASTRO, Iná; CORRÊA, Roberto L.;GOMES, Paulo C. (Org’s). Geografia: Conceitos e Temas. Rio de Janeiro: Bertrand Brasil, 1995. p.140-164

SACK, R. D. Human Territoriality. Its Theory and History. Cambridge: Cambridge University Press, 1986. 272p.

SOUZA SANTOS, B. Pela Mão de Alice. São Paulo: Contexto, 2010. 348p.

SOJA. E. Postmetropolis - Critical studies of cities and regions. Oxford: Bleckwell, 2000. 440p. 
Geografias pós-modernas. Rio de janeiro, Jorge Zahar, 1993. 324p.

Artigo encaminhado para publicação em maio de 2012.

Artigo aceito para publicação em julho de 2012. 